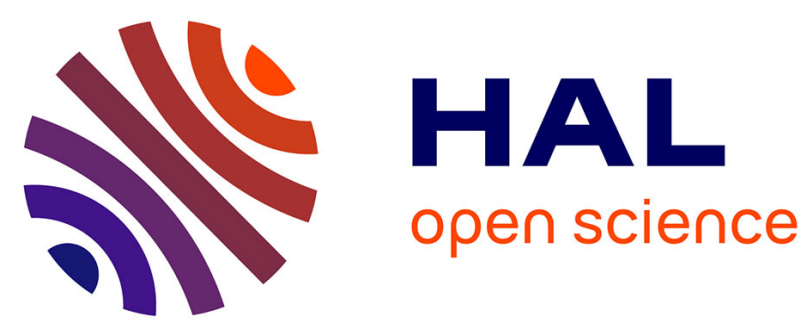

\title{
Migration analysis of epoxidized soybean oil and other plasticizers in commercial lids for food packaging by gas chromatography-mass spectrometry
}

Carmen Bueno-Ferrer, Alfonso Jiménez, Maria del Carmen Garrigós

\section{- To cite this version:}

Carmen Bueno-Ferrer, Alfonso Jiménez, Maria del Carmen Garrigós. Migration analysis of epoxidized soybean oil and other plasticizers in commercial lids for food packaging by gas chromatography-mass spectrometry. Food Additives and Contaminants, 2010, 27 (10), pp.1469. 10.1080/19440049.2010.502129 . hal-00608723

\section{HAL Id: hal-00608723 https://hal.science/hal-00608723}

Submitted on 14 Jul 2011

HAL is a multi-disciplinary open access archive for the deposit and dissemination of scientific research documents, whether they are published or not. The documents may come from teaching and research institutions in France or abroad, or from public or private research centers.
L'archive ouverte pluridisciplinaire HAL, est destinée au dépôt et à la diffusion de documents scientifiques de niveau recherche, publiés ou non, émanant des établissements d'enseignement et de recherche français ou étrangers, des laboratoires publics ou privés. 


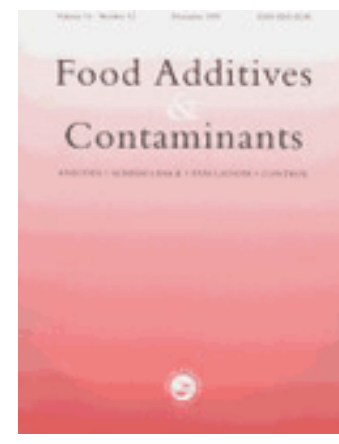

\section{Migration analysis of epoxidized soybean oil and other plasticizers in commercial lids for food packaging by gas chromatography-mass spectrometry}

\begin{tabular}{|r|l|}
\hline Journal: & Food Additives and Contaminants \\
\hline Manuscript ID: & TFAC-2009-427.R1 \\
\hline Manuscript Type: & Original Research Paper \\
\hline Author: & 03-Jun-2010 \\
\hline Complete List of Authors: & $\begin{array}{l}\text { Bueno-Ferrer, Carmen; University of Alicante, Analytical Chemistry, } \\
\text { Nutrition and Food Science } \\
\text { Jiménez, Alfonso; University of Alicante, Analytical Chemistry, } \\
\text { Nutrition and Food Science } \\
\text { Garrigós, Maria del Carmen; University of Alicante, Analytical } \\
\text { Chemistry, Nutrition and Food Science }\end{array}$ \\
\hline Methods/Techniques: & Chromatography - GC/MS, Method validation \\
\hline Additives/Contaminants: & $\begin{array}{l}\text { Packaging - ESBO, Packaging plasticisers, Food contact materials, } \\
\text { Migration }\end{array}$ \\
\hline Food Types: & Baby food, Oils and fats, Vegetables \\
\hline
\end{tabular}

\section{SCHOLARONE" Manuscripts}




\title{
Migration analysis of epoxidized soybean oil and other plasticizers in commercial lids for food packaging by gas chromatography-mass spectrometry \\ C. Bueno-Ferrer*, A. Jiménez and M. C. Garrigós
}

Analytical Chemistry, Nutrition \& Food Sciences Department, University of Alicante, P.O. Box 99, E-03080, Alicante, Spain.

*Corresponding author.

Email: carmen.bueno@ua.es

Tel. +34 965903400 (ext 3117); Fax +34 965903527

\begin{abstract}
A modification of the method of Castle et al. (1988a) for the analysis of epoxidized soybean oil (ESBO) is proposed in order to simplify the analysis and reduce the time and consumption of reagents. The proposed modifications, particularly the elimination of the internal standard, resulted in a simpler, faster and more economical method. A complete analytical validation, including evaluation of the main analytical parameters, such as detection and quantification limits, linearity, working range, precision, accuracy and selectivity, was carried out. The data demonstrated the suitability of the proposed method for the determination of ESBO in polymer matrices. A specific migration study for ESBO in different food simulants (fat and aqueous) was carried out by applying the method to PVC materials prepared with known amounts of ESBO, as well as some commercial lids. High levels of migration of ESBO into fat simulants were found. In the case of commercial lids, in addition to ESBO, some other plasticizers such as citrates, adipates and sebacates were found and quantified to establish their migration under different conditions of use.
\end{abstract}


Keywords: epoxidized soybean oil, plasticizers, migration, validation, gas chromatography/mass spectrometry.

\section{Introduction}

Epoxidized soybean oil (ESBO) is a vegetable oil widely used as plasticizer and/or stabilizer for poly(vinyl chloride) (PVC) formulations used in food contact materials (Lau et al. 2000; Fankhauser-Noti et al. 2006; Duffy and Gibney 2007; Biedermann et al. 2008; Pedersen et al. 2008). These formulations have shown some applications, such as gaskets of lids for glass jars or in domestic films where PVC usually contains 35-45 wt\% of plasticizer (Fankhauser-Noti et al. 2005a; Fankhauser-Noti and Grob 2006; Biedermann et al. 2008; Pedersen et al. 2008). ESBO, as well as some low molar mass plasticizers, such as acetyl tributyl citrate (ATBC), dioctyl adipate (DOA) or dibutyl sebacate (DBS), has grown during the last years as a valid alternative to phthalates, under discussion because of their potential toxicity to humans (Rhee et al. 2002). ESBO shows relatively good compatibility with PVC, low toxicity to humans (BIBRA 1988; ECB 2000; EFSA 2004) and a biodegradable nature (Choi and Park 2004; Liu et al. 2006; Behera and Banthia 2008; Bouchareb and Benaniba 2008; Liu and Erhan 2008) However, its migration to foodstuff is still under study, in particular in high-fat foods (Fankhauser-Noti et al. 2005a; Fankhauser-Noti et al. 2006; Biedermann et al. 2008; Grob and Marmiroli 2009).

ESBO is listed as an authorized substance according to food packaging materials legislation (Pedersen et al. 2008; European Commission 2002). The specific migration limit for ESBO is 60 $\mathrm{mg} \mathrm{kg}^{-1}$ food simulant which corresponds to the overall migration limit (European Commission 2007). In this regulation, the European Commission lowered the ESBO migration limit to $30 \mathrm{mg}$ $\mathrm{kg}^{-1}$ for infant food, since the tolerable daily intake (TDI) for $1 \mathrm{mg} \mathrm{kg}^{-1}$ body weight was often exceeded (EFSA 2004; EFSA 2006). 
Several analytical methods were reported for the analysis of ESBO in PVC gaskets and food. Castle et al. (1988a; 1988b) developed a specific method for analyzing ESBO in food that has been routinely used in further studies (EFSA 2004; Fankhauser-Noti et al. 2005a; Duffy and Gibney 2007). In this method, standards prepared from a commercial ESBO solution and fat extracts obtained from food samples were first transmethylated and then derivatized to form 1,3-dioxolane groups of the ESBO fatty acids. Dioxolanes provide stability to the epoxidized compounds, allowing optimization of the gas chromatographic separation from fatty acid methyl esters and shifting the mass spectra to higher and more selective masses (Rothenbacher and Schwack 2007). An internal standard (IS) was firstly epoxidized and fully derivatized in the same way as ESBO standards and it was used for quantification purposes. However, the synthesis of the IS was a long and complicated process involving a high number of analytical steps where the initial weight, epoxidation yield and purity of the product were not ensured (Fankhauser-Noti et al. 2005b). The same authors proposed a method where after transterification of epoxidized triglycerides, the methyl esters of diepoxy linoleic acid and two internal standards were isolated by HPLC and further transferred to a GC equipped with an FID. Suman et al. (2005) developed a method for the analysis of ESBO in foodstuff based on reversed phase liquid chromatography interfaced with electrospray ion-trap tandem mass spectrometry (MS), which included a simple procedure for sample preparation with an extraction step and no further purification prior to the analysis. BiedermannBrem et al. (2007) developed a method without prior extraction, using a polar GC column and detection by FID or MS for samples with interfering components. The main drawback of this method was the use of MS in chemical ionization mode (positive and negative ion monitoring), that is not commonly available in food control laboratories. Rothenbacher et al. (2007) developed a method for the analysis of ESBO in food by GC/MS and GC/MS/MS using a stable isotope dilution from synthesized ethyl 9,10,12,13-diepoxyoctadecanoate by following the epoxidation method already described by Castle et al. (1988a). 
The aim of this work is to simplify these methods permitting easier and faster determinations of ESBO in PVC materials for food packaging. The work presents a modification of the method developed by Castle et al. (1988a; 1988b) where the use of IS would be unnecessary. Moreover, some changes in the experimental method (transmethylation and synthesis of 1,3-dioxolane derivatives) and optimization of chromatographic conditions are proposed resulting in a considerable reduction in analysis time. This method was validated including evaluation on detection and quantification limits, linearity, working range, precision, accuracy and selectivity. Finally, migration studies were carried out by applying this modified method to PVC-ESBO samples in two different food simulants as well as to commercial lids from nine different food jars, including baby food. Migration analysis in real samples was also carried out and other plasticizers such as ATBC, DOA and DBS were determined.

\section{Experimental}

\section{Chemicals}

Commercial ESBO was supplied by Traquisa S.L. (Barcelona, Spain). ATBC, DOA and DBS were purchased from Sigma-Aldrich (Madrid, Spain). PVC resin Lacovyl PB1172H with k value 67.0 was purchased from Atofina UK Ltd. (Cheshire, United Kingdom).

All chemicals were analytical grade unless specified otherwise. Metallic sodium, methanol (GC grade), sodium chloride and absolute ethanol were purchased from Panreac (Barcelona, Spain). Cyclopentanone, boron trifluoride etherate and n-hexane (GC grade) were supplied by Merck (Darmstadt, Germany). 2,2,4-Trimethylpentane (iso-octane) and acetic acid were purchased from Fluka (Steinheim, Germany). Commercial virgin olive oil was used in specific migration tests for PVC-ESBO samples in contact with fat food. Water was distilled and passed through a Milli-Q Water System (Millipore, Bedford, MA, USA) prior to use. Sodium methoxide (NaOMe) 0.150 M solution was prepared by dissolving $3.406 \mathrm{~g}$ metallic sodium in methanol. 
Methods

ESBO standards were obtained by transmethylation and synthesis of 1,3-dioxolane derivatives as shown in Figure 1. This procedure was performed in triplicate and it was based on Castle et al. method (1988b). Since the main goal of these modifications was to avoid the use of an IS, ESBO standards were prepared by weight. The three obtained stock solutions $\left(65000 \mathrm{mg} \mathrm{kg}^{-1}\right)$ were stored at $-18{ }^{\circ} \mathrm{C}$. ESBO calibration standards for $\mathrm{GC} / \mathrm{MS}$ analysis were prepared by appropriately dissolving each stock solution in n-hexane.

Unlike ESBO, other plasticizers such ATBC, DOA and DBS did not need previous derivatization for GC/MS analysis, due to their lower molar mass. A multi-standard plasticizer solution $1000 \mathrm{mg} \mathrm{kg}^{-1}$ in $\mathrm{n}$-hexane was prepared for the migration study in commercial lids.

\section{GC/MS Analysis}

GC/MS analysis was carried out by using HP/Agilent Technologies 6890N (Palo Alto, CA, USA) gas chromatograph coupled to Agilent Technologies 5973N mass spectrometer operating in electronic impact (EI) ionization mode $(70 \mathrm{eV})$. A DB-5MS capillary column (30 m x $0.25 \mathrm{~mm}$ I.D. x $0.25 \mu \mathrm{m}$ film thickness) (Teknokroma, Barcelona, Spain) and a split-splitless injector were used. Helium was used as the carrier gas with $1 \mathrm{~mL} \mathrm{~min}^{-1}$ flow rate. Temperatures for injector and detector were $290{ }^{\circ} \mathrm{C}$ and $300{ }^{\circ} \mathrm{C}$, respectively. For ESBO determination, the column temperature was programmed from $140{ }^{\circ} \mathrm{C}$ (hold $2 \mathrm{~min}$ ) to $300{ }^{\circ} \mathrm{C}$ at $20^{\circ} \mathrm{C} \mathrm{min}-1$ heating rate (hold $10 \mathrm{~min}$ ). Samples $(1 \mu \mathrm{L})$ were injected in the split mode (split ratio 1:40). Determination of derivatized epoxy fatty acids was performed by using selected ion monitoring (SIM) mode focused on $\mathrm{m} / \mathrm{z} 309$, by comparing chromatographic peak areas for migration extracts with those of standards in the same concentration range. Other ions used for identification were those with $\mathrm{m} / \mathrm{z} 277,367,396,465$ and 494. 
For ATBC, DOA and DBS determination, the column temperature was programmed from $80^{\circ} \mathrm{C}$ to $160{ }^{\circ} \mathrm{C}$ at $30{ }^{\circ} \mathrm{C} \mathrm{min}{ }^{-1}$ heating rate and from $160{ }^{\circ} \mathrm{C}$ to $320{ }^{\circ} \mathrm{C}$ at $15^{\circ} \mathrm{C} \mathrm{min}{ }^{-1}$ heating rate (hold $7 \mathrm{~min}$ ). Samples $(1 \mu \mathrm{L}$ ) were injected in the split mode (split ratio 1:25) and quantification of plasticizers was performed by using scan mode $(50-550 \mathrm{~m} / \mathrm{z})$.

\section{Specific migration study \\ PVC-ESBO samples}

For the migration study, PVC samples with known amounts of ESBO were prepared at three different plasticizer concentrations (30, 40 and $50 \mathrm{wt} \%)$, since they are common in the preparation of plasticized PVC for food contact materials (Fankhauser-Noti et al. 2006; Ežerkis et al. 2007; Grob 2007; Biedermann et al. 2008). PVC and ESBO were mixed in a planetary mixer KAPL 5KPM5 (St. Joseph, MI, USA) at $23 \pm 2{ }^{\circ} \mathrm{C}$ for $30 \mathrm{~min}$. Plastisols were degassed using a vacuum chamber HEK-GmbH MCP (Lübeck, Germany) to remove air bubbles and further cured in an oven at $170^{\circ} \mathrm{C}$ during $8 \mathrm{~min}$ to obtain layers with thickness $0.34 \pm 0.04 \mathrm{~cm}$.

A general study for ESBO specific migration in olive oil and distilled water was carried out for all the prepared PVC-ESBO materials by application of the method developed in this work. Olive oil and distilled water were selected since they cover most of the real applications of commercial lids and tests were performed in triplicate. $10 \mathrm{~cm}^{2}$ samples were cut and placed in contact with $10.0 \mathrm{~mL}$ of olive oil and distilled water by total immersion at $40^{\circ} \mathrm{C}$ for 10 days, since these are the general conditions for food to be stored at room temperature for more than 24 hours contact time (CEN 2002; CEN 2004). ESBO content in each food simulant was then analyzed by direct application of the method developed in this work. Distilled water extracts required prior evaporation to dryness in a rotary evaporator Multivapor BÜCHI P-6, (Flawil, Switzerland) for further testing. A blank test for each simulant was also performed. 


\section{Commercial lids}

Specific migration tests from commercial lids were performed in triplicate following EN 13130-1 Standard (CEN 2004). Glass jars were filled with the appropriate food simulant according to their $\mathrm{pH}$ value. Distilled water was selected for asparagus since $\mathrm{pH}$ was determined to be higher than 4.5 and an aqueous solution $(3 \% \mathrm{w} / \mathrm{v})$ of acetic acid for pickled gherkins, jam and three different fruit-based baby foods since their $\mathrm{pH}$ values were lower than 4.5. For jars with fat foods (pate, pesto sauce and mayonnaise), ethanol (95\%v/v) and iso-octane were selected as alternative fat simulants, as it is accepted in regulations (EN-13013, CEN 2004) and it has been common in recent research work (Tovar et al. 2005, Kubwabo et al. 2009). A blank test for each simulant was also performed. Glass jars were closed with the lid and turned on its head during 10 days at $40{ }^{\circ} \mathrm{C}$, except in the case of those samples with iso-octane which were exposed to 2 days at $20{ }^{\circ} \mathrm{C}$ according to the EN-13013. All liquids were subsequently evaporated to dryness in a rotary evaporator.

ESBO migration from gaskets was quantified by application of the developed method to dry samples before GC/MS analysis, while ATBC, DOA and DBS were determined by dilution in nhexane prior to the injection in the gas chromatograph.

\section{Results and discussion}

\section{ESBO identification and quantification}

ESBO mainly consists of some triglycerides, whose average composition in fatty acids is about $11 \%$ palmitic (16:0), 4\% stearic (18:0), 23\% epoxidized oleic (18:1E), 55\% diepoxidized linoleic (18:2E), and 8\% triepoxidized linolenic (18:3E) (EFSA 2004; Fankhauser-Noti et al. 2006; Yang et al. 2008; Nor Hayati et al. 2009). ESBO identification was based in a single fatty acid, i.e. derivatized diepoxidized linoleic acid (C18:2E), due to its high concentration in ESBO and no natural occurrence in food (Castle et al. 1988b; Berdeaux et al. 1999). The synthesis of 1,3- 
dioxolanes developed by Castle et al. (1988a) enabled an increase in the molar mass of the epoxidized fatty acids resulting in later elution than for any other fatty acids present in ESBO or in food samples, permitting a clear identification and quantification. The use of the modified method proposed here preserved the same chromatographic behaviour for 1,3-dioxolanes (Figure 2). Derivatized diepoxidized linoleic acid showed two chromatographic peaks (4 and 5 in Fig. 2), corresponding to two stereoisomers with a characteristic mass ratio based on $\mathrm{m} / \mathrm{z} 277$ and 309 . The most abundant ion (m/z 309) was selected for quantification.

\section{Validation of the developed method}

A validation procedure for the method developed in the present work was carried out and the main parameters typically used to ensure reliable results for analytical methods were determined (EMEA 1996).

\section{Linearity, Detection and Quantification Limits (LOD and LOQ)}

Three different stock solutions with a concentration near $65000 \mathrm{mg} \mathrm{kg}{ }^{-1}$ were prepared separately. Five calibration standards with concentrations between 1.0 and $9.0 \mathrm{mg} \mathrm{kg}^{-1}$ were prepared from each stock solution to evaluate linearity and they were injected in triplicate. This range was selected because it was necessary to ensure linearity at low concentrations with a working range near LOD and LOQ. Regression parameters for the obtained calibration curves are indicated in Table 1. Results showed a linear behaviour for the three standard series calibration curves over the explored concentration range with acceptable determination coefficient $\left(\mathrm{R}^{2}\right)$ values, despite all of them were lower than 0.995 due to the low concentrations and close range used in this study. High values were obtained for intercept standard deviations (SD) and relative standard deviations (RSD) from slopes and intercepts. This fact could be attributed to the high number of steps included in the experimental method and the sum of uncertainties from each stage which resulted in relatively high deviations between results. 
LOD and LOQ were calculated with two different methods: One of them was by using the "signal to noise" (S/N) ratio from chromatograms corresponding to the lowest standard of each of the three calibration graphs. LOQ was determined as the S/N of 10:1 and LOD was determined as S/N of 3:1 of average value of ESBO peak obtained during linearity experiments at low concentration. The second method was by using regression parameters of the three calibration graphs. This one is considered more reliable as regression errors are integrated in the obtained values and resulted in lower LOD and LOQ values as indicated in Table 2. The high values obtained for RSD were attributed to the use of three different stock solutions prepared separately. In summary, LOD and LOQ were clearly lower than the ESBO migration limits and sensitive enough to assess the possibility of this method to be applied for ESBO specific migration tests even at low concentration levels.

\section{Precision}

In this validation study, precision was calculated in terms of intraday repeatability as RSD (\%) of peak areas obtained from the three different standard series at three concentration levels (5.0, 7.0 and $9.0 \mathrm{mg} \mathrm{kg}^{-1}$ solution of ESBO) in triplicate. The same equipment was used and procedure over the whole analysis was followed by the same analyst to reduce human errors. Obtained results were lower than $5 \%$ in all cases, confirming an acceptable repeatability of this method when compared with 7\% obtained by Castle et al (1988b).

\section{Accuracy}

This parameter was evaluated by calculating the percent recovery of known spiked amounts of ESBO in olive oil near the legal migration limits. Four concentration levels (30, 60, 100 and 200 mg ESBO kg${ }^{-1}$ olive oil) were used for such tests performed in triplicate. It should be mentioned that olive oil is a complex matrix because of its high content in unsaturated fatty acids. In order to quantify the ESBO concentration in the spiked samples, it was necessary to draw another 
calibration curve with a higher concentration range. Satisfactory values $\left(\mathrm{R}^{2}>0.998\right)$ were obtained in this case, better than those shown in Table 1 at low ESBO concentrations and comparable to those obtained by Castle et al. (1988b). Good recovery percentages and RSD values were obtained for all concentration levels, as shown in Table 3. These results could be considered acceptable for the analysis of real samples and also similar to those obtained by Castle et al (1988b), which ranged from $97 \%$ to $109 \%$ by spiking food samples with ESBO at the same concentration level (from 110 to $170 \mathrm{mg} \mathrm{kg}^{-1}$ ).

\section{Working range}

The method working range was evaluated from the two calibration curves prepared for validation at different concentration levels, as previously indicated. LOQ was taken as the lower limit for such range $\left(3.6 \mathrm{mg} \mathrm{kg}^{-1} \mathrm{ESBO}\right)$ while the highest concentration standard used in the accuracy evaluation was selected for the upper limit (126.0 mg kg-1 ESBO). It must be noticed that different values of the working range were obtained if expressed as $\mathrm{mg} \mathrm{kg}^{-1}$ ESBO or $\mathrm{mg} \mathrm{kg}^{-1}$ food. Considering the second case as the most representative for comparison with legal limits, the working range for this method was $16-438 \mathrm{mg} \mathrm{kg}^{-1}$ food, including the ESBO migration legal limits indicated in the Introduction section. Therefore, this method could be considered completely valid to be used in ESBO migration studies.

\section{Selectivity}

Selectivity of this method was calculated by considering the synthesis reaction to form 1,3dioxolane derivatives from epoxidized fatty acids. Results were essentially the same as those obtained by Castle et al (1988b). Derivatized monoepoxidized oleic acid could not be used for such purpose since the specific ion $\mathrm{m} / \mathrm{z} 367$ is also observed by natural occurrence in food, making it 
unable for identification as shown in Figure 3. In consequence, the derivatized diepoxidized linoleic acid with specific $\mathrm{m} / \mathrm{z}$ ratio $277 / 309$ was used for this study.

\section{Specific migration study}

PVC-ESBO samples

Once the analytical method developed and validated in this work showed its reliability for ESBO determinations, it was used to evaluate the specific migration of ESBO in real conditions. In both cases a calibration curve was prepared with 14 standards ranging from 3.0 to $600 \mathrm{mg}$ ESBO $\mathrm{kg}^{-1}$ solution in order to obtain a wide concentration range for quantification.

As shown in Figure 4, intense chromatographic peaks corresponding to high migration values

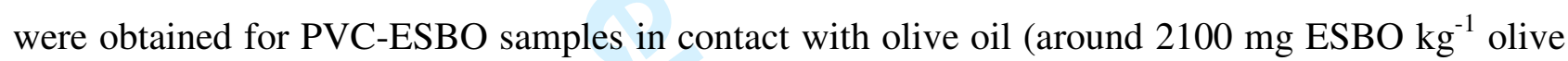
oil in the case of the $30 \%$ ESBO sample and even more intense peaks for higher concentrations). These high migration results were attributed to the massive exchange of fatty acids from the plastic sample with ESBO and the food matrix (olive oil), due to their high similarity in molecular composition. Moreover, an inadequate short curing time or a high ESBO concentration in the PVCESBO materials could involve a lower interaction between both components. The olive oil blank sample yielded no detectable peaks for derivatized diepoxidized linoleic acid as it can be observed in Figure 4. Therefore, it could be concluded that the studied PVC-ESBO formulations would not be suitable for packaging use in food with very high fat content.

A similar migration study performed in distilled water yielded no detectable values for ESBO. Therefore, all the studied formulations could be suitable for aqueous food packaging, making ESBO a promising alternative for PVC formulations since their low toxicity compared to phthalates (Rhee et al. 2002) as well as their biodegradable nature (Choi and Park 2004; Liu et al. 2006; Behera and Banthia 2008; Bouchareb and Benaniba 2008; Liu and Erhan 2008). 


\section{Commercial gaskets}

The evaluation of the suitability of the developed method for ESBO determination in real samples was carried out by selecting target food products packaged in glass jars. Nine different commercial lids were selected for the specific migration testing and an additional screening analysis of other plasticizers commonly used in gaskets was carried out in order to study the current compliance level of migration in food contact materials in the Spanish market. All tests were performed in triplicate. The obtained results (Table 4) revealed that the highest amounts of migrated plasticizers were found in alternative fat simulants, particularly in ethanol $95 \%(\mathrm{v} / \mathrm{v})$. Some plasticizers were found in the three analyzed lids from fat food, and all of them migrated in amounts higher than the current legal migration limits. Two of them showed high levels of ESBO and, in the case of pate lid, even above the current transitional limit of $300 \mathrm{mg} \mathrm{kg}^{-1}$ (European Commission 2007; European Commission 2008). The third sample (pesto sauce) showed high levels of ATBC. Some of the standard deviations obtained from triplicates were high although they could be considered acceptable for commercial samples. In the case of aqueous simulants, migration from lids was barely detected. In the case of baby fruit lids no detectable values were obtained for any sample, as it could be expected, because of the high hydrophobic character of common plasticizers.

\section{Conclusions}

A simpler, faster and more economical method for ESBO determination was developed and it was compared to the well-known one reported by Castle et al. (1988a.) The main difference between both methods consists of the elimination in the use of a costly internal standard giving added value to this development since it permits the determination of ESBO in plasticized PVC materials avoiding the use of tedious and expensive methods. The analytical validation of this method was carried out and gave indication on its reliability for application to food and materials in direct contact. Satisfactory results were obtained for precision and accuracy, with comparable or 
even better values than the reference method. The working range for this method was 16-438 mg ESBO $\mathrm{kg}^{-1}$ food including all the ESBO migration legal limits. As the result of the specific migration analysis, PVC-ESBO formulations prepared in the laboratory were not suitable for packaging of highly fat food, where massive exchange of fatty acids between the plastic material and simulant could occur due to their high similarity in molecular composition; but they could be used without restrictions for aqueous food packaging. Migration analysis from commercial lids confirmed that the amounts obtained for ESBO exceeded legal migration limits in two of the three analyzed lids from fat foods, with the third one exceeding the ATBC legal migration limit. No other remarkable migration in other simulants was observed.

\section{Acknowledgements}

The authors would like to thank Traquisa S.A. (Barcelona, Spain) for kindly supplying ESBO; and also Institute Juan Gil Albert (Diputación de Alicante, Spain) and University of Alicante (SICyT UAUSTI09-05) for their financial support. 


\section{References}

Behera D, Banthia AK. 2008. Synthesis, characterization, and kinetics study of thermal decomposition of epoxidized soybean oil acrylate. J Appl Polym Sci. 109:2583-2590.

Berdeaux O, Márquez-Ruiz G, Dobarganes MC. 1999. Characterization, quantitation and evolution of monoepoxy compounds formed in model systems of fatty acid methyl esters and monoacid triglycerides heated at high temperature. Grasas y Aceites. 50(1):53-59.

BIBRA. 1988. British Industrial Biological Research Association Industrial (BIBRA): Toxicity profile: epoxidised soybean oil. Carlshalton, Surrey, UK.

Biedermann M, Fiselier K, Grob K. 2008. Testing migration from the PVC gaskets in metal closures into oily foods. Trends Food Sci Technol. 19:145-155.

Biedermann M, Fiselier K, Marmiroli G, Avanzini G, Rutschmann E, Pfenninger S, Grob K. 2008. Migration from the gaskets of lids into oily foods: first results on polyadipates. Eur Food Res Technol. 226:1399-1407.

Biedermann S, Biedermann M, Fankhauser-Noti A, Grob K, Helling R. 2007. Determination of epoxidized soy bean oil (ESBO) in oily foods by GC-FID or GC-MS analysis of the methyl diepoxy linoleate. Eur Food Res Technol. 224(3):309-314.

Bouchareb B, Benaniba MT. 2008. Effects of epoxidized sunflower oil on the mechanical and dynamical analysis of the plasticized poly(vinyl chloride).J Appl Polym Sci. 107:3442-3450.

Castle L, Sharman M, Gilbert J. 1988a. Analysis of the epoxidised soya bean oil additive in plastics by gas chromatography. J. Chromatogr. 437:274-280.

Castle L, Sharman M, Gilbert J. 1988b. Gas Chromatographic- Mass Spectrometric Determination of Epoxidized Soybean Oil Contamination of Foods by Migration from Plastic Packaging. J Assoc Off Anal Chem. 71:1183-1186.

Choi JS, Park WH. 2004. Effect of biodegradable plasticizers on thermal and mechanical properties of poly(3-hydroxybutyrate). Polym Testing. 23(4):455-460. 
Duffy E, Gibney M. 2007. Use of a food-consumption database with packaging information to estimate exposure to food-packaging migrants: Expoxidized soybean oil and styrene monomer. $\mathbf{J}$ Food Addit Contam. 24(2):216-225.

European Agency for the Evaluation of Medicinal Products (EMEA). 1996. Validation of Analytical Procedures: Methodology CPMP/ICH/281/95, Final (ICH Topic Q2B, Step 4). Available from: http://www.emea.europa.eu/pdfs/human/ich/028195en.pdf (accessed 2009 December).

European Chemicals Bureau (ECB). 2000. IUCLID (International Uniform Chemical Information Database) for epoxidized soybean oil. Available from: http://ecb.jrc.ec.europa.eu/IUCLIDDataSheets/8013078.pdf (accessed 2009 December)

European Commission (EC). 2002. Commission Directive 2002/72/EC of 6 August 2002 relating to plastic materials and articles intended to come into contact with foodstuffs. Official Journal of the European Communities L 220:18.

European Commission (EC). 2007. Commission Regulation 372/2007/EC of 2 April 2007 laying down transitional migration limits for plasticizers in gaskets in lids intended to come into contact with foods. Official Journal of the European Union L 92:9.

European Commission (EC). 2008. Commission Regulation 597/2008 of 24 June 2008 amending regulation 372/2007/EC. Official Journal of the European Union L 164:12.

European Committee for Standardization (CEN). 2002. EN 1186, June 2002, Materials and articles in contact with foodstuffs.

European Committee for Standardization (CEN). 2004. EN 13130-1, May 2004, Materials and articles in contact with foodstuffs. Plastics substances subject to limitation. Guide to test methods for the specific migration of substances from plastics to foods and food simulants and the determination of substances in plastics and the selection of conditions of exposure to food simulants. 
European Council. 1982. Council Directive 82/711/EEC of 18 October 1982 laying down the basic rules necessary for testing migration of the constituents of plastic materials and articles intended to come into contact with foodstuffs. Official Journal. L 297:26-30.

European Food Safety Authority (EFSA). 2004. Opinion of the Scientific Panel on Food Additives, Flavourings, Processing Aid and Materials in Contact with Food (AFC) on a request from the Commission related to the use of Epoxidized soybean oil in food contact materials adopted on 26 May 2004. EFSA $24: 1 . \quad$ J. Available http://www.efsa.europa.eu/cs/BlobServer/Scientific_Opinion/opinion_afc10_ej64_epox_soyoil_e n1.pdf?ssbinary=true (accessed 2009 December).

European Food Safety Authority (EFSA). 2006. Opinion of the Scientific Panel on Food Additives, Flavourings, Processing Aid and Materials in Contact with Food (AFC) related to exposure of adults to epoxidized soybean oil used in food contact materials adopted on 16 March 2006. EFSA $\mathrm{J}$. $332: 2$. Available from: http://www.efsa.europa.eu/cs/BlobServer/Scientific_Opinion/afc_op_ej332_esbo_op_en1.pdf?ssb inary=true (accessed 2009 October).

Ežerkis Z, Morkūnas V, Suman M, Simoneau C. 2007. Analytical screening of polyadipates and other plasticizers in poly(vinyl chloride) gasket seals and in fatty food by gas chromatographymass spectrometry. Anal Chim Acta. 604:29-38.

Fankhauser-Noti A, Grob K. 2006. Migration of plasticizers from PVC gaskets of lids for glass jars into oily food: Amount of gasket material in food contact, proportion of plasticizer migrating into food and compliance testing by simulation. Trends Food Sci Technol. 17:105-112.

Fankhauser-Noti A, Biedermann S, Grob K. 2006. PVC plasticizers/additives migrating from the gaskets of metal closures into oily food: Swiss market survey June 2005. Eur Food Res Technol. 223(4):447-453. 
Fankhauser-Noti A, Fiselier K, Biedermann S, Biedermann M, Grob K, Armellini F, Rieger K., Skjevrak I. 2005a. Epoxidized soybean oil (ESBO) migrating from the gaskets of lids into food packed in glass jars. Eur Food Res Technol. 221:416-422.

Fankhauser-Noti A, Fiselier K, Biedermann S, Grob K. 2006. Assessment of epoxidized soy bean oil (ESBO) migrating into foods: Comparison with ESBO-like epoxy fatty acids in our normal diet. J Food Chem. Toxicol. 44:1279-1286.

Fankhauser-Noti A, Fiselier K, Biedermann-Brem S, Grob K. 2005b. Epoxidized soy bean oil migrating from the gaskets of lids into food packed in glass jars. Analysis by on-line liquid chromatography-gas chromatography. J Chromatogr A. 1082:214-219.

Grob K, Marmiroli G. 2009. Assurance of compliance within the production chain of food contact materials by good manufacturing practice and documentation - Part 3: Lids for glass jars as an example. Food Control. 20(5):491-500.

Grob K. 2007. Verification of results to improve the quality of analytical data: A proposal. J Chromatogr A. 1150(1-2):93-99.

Information Section. 1996. Information Section: Committees on Toxicity, Mutagenicity and Carcinogenicity. Food Chem Toxicol. 34(2):227-229.

Kubwabo C, Kosarac I, Stewart B, Gauthier BR, Lalonde K, Lalonde PJ. 2009. Migration of bisphenol A from plastic baby bottles, baby bottle liners and reusable polycarbonate drinking bottles. Food Addit Contam: Part A. 26:928-937

Lau O, Wong WS. 2000. Contamination in food from packaging material. J Chromatogr A. $882: 255-270$.

Liu Z, Erhan SZ, Akin DE, Barton FE. 2006."Green" composites from renewable resources: Preparation of epoxidized soybean oil and flax fiber composites. J Agric Food Chem. 54:21342137. 
Liu Z, Erhan SZ. 2008. "Green" composites and nanocomposites from soybean oil. J Mater Sci Eng. 483-484:708-711.

Nor Hayati I, Che Man YB, Ping Tan C, Nor Aini I. 2009. Physicochemical characteristics of soybean oil, palm kernel olein, and their binary blends. International J Food Sci Technol. 44(1):152-161.

Pedersen GA, Jensen LK, Fankhauser A, Biedermann S, Petersen JH, Fabech B. 2008. Migration of epoxidized soybean oil (ESBO) and phthalates from twist closures into food and enforcement of the overall migration limit, Food Addit Contam. 25(4):503-510.

Rhee GS, Kim SH, Kim SS, Sohn, KH, Kwack SJ, Kim BH, Park KL. 2002. Comparison of embryotoxicity of ESBO and phthalate esters using an in vitro battery system. J Toxicol In Vitro. $16: 443-448$.

Rothenbacher T, Schwack W. 2007. Determination of epoxidized soybean oil by gas chromatography/single quadrupole and tandem mass spectrometry stable isotope dilution assay. Rapid Commun Mass Spectrom. 21(12):1937-1943.

Suman M, La Tegola S, Catellani D, Bersellini U. 2005. Liquid Chromatography-Electrospray Ionization-Tandem Mass Spectrometry Method for the Determination of Epoxidized Soybean Oil in Food Products. J Agric Food Chem. 53:9879-9884.

Tovar L, Salafranca J, Sánchez C, Nerín C. 2005. Migration Studies To Assess the Safety in Use of a New Antioxidant Active Packaging. J Agric Food Chem. 53:5270-5275

Yang L, Dai H, Yi A, Lin B, Li G. 2008. Structure and properties of partially epoxidized soybean oil. J Therm Anal Cal. 93(3):875-879. 


\section{FIGURE CAPTIONS}

Figure 1. Scheme of ESBO stock solution preparation.

Figure 2. Chromatogram of commercial ESBO obtained by application of the developed method. Peaks: 1. (C16:0)Me; 2. (C18:0)Me; 3. 1,3-dioxolane of (C18:1E)Me; 4-5. Stereoisomers of 1, 3dioxolane of (C18:2E)Me.

Figure 3. Chromatograms of an olive oil sample and an olive oil sample after contact with ESBO and migration analysis $\left(10\right.$ days, $\left.40^{\circ} \mathrm{C}\right)$. Peaks: 1.1,3-dioxolane of (C18:1E)Me; 2-3. Stereoisomers of 1,3-dioxolane of (C18:2E)Me.

Figure 4. Chromatograms from olive oil samples after contact with PVC-ESBO samples. Peaks: Stereoisomers of 1, 3-dioxolane of (C18:2E)Me. 
Table 1

\begin{tabular}{lcc}
\hline & Castle method & Proposed method \\
\hline Experimental conditions & & \\
NaOMe concentration $(\mathrm{M})$ & 0.02 & 0.150 \\
Transmethylation temperature $\left({ }^{\circ} \mathrm{C}\right)$ & 60 & 70 \\
Transmethylation time $(\mathrm{min})$ & 120 & 5 \\
Calibration & Internal Standard & External Standards \\
Solvent standards dilution & Acetone-n-Hexane $(5+95, \mathrm{v} / \mathrm{v})$ & \\
& & \\
Chromatographic conditions & $1: 20$ & $1: 40$ \\
Split Ratio & 1.7 & 1.0 \\
Injection Volume $(\mu \mathrm{L})$ & 280 & 290 \\
Injector Temperature $\left({ }^{\circ} \mathrm{C}\right)$ & $300($ Isothermal) & Ramp 140 to $300\left(20^{\circ} \mathrm{C} \mathrm{min}^{-1}\right)$ \\
Oven Temperature $\left({ }^{\circ} \mathrm{C}\right)$ & &
\end{tabular}


Table 2

\begin{tabular}{cccc}
\hline & slope \pm SD & intercept \pm SD & $\mathbf{R}^{\mathbf{2}}$ \\
\hline $\mathbf{1}$ & $7958 \pm 585$ & $13013 \pm 3245$ & 0.9841 \\
$\mathbf{2}$ & $6253 \pm 396$ & $8022 \pm 2224$ & 0.9913 \\
$\mathbf{3}$ & $9369 \pm 493$ & $10850 \pm 2787$ & 0.9943 \\
RSD $(\%)$ & 19.9 & 23.5 & - \\
\hline
\end{tabular}


Table 3

\begin{tabular}{lcc}
\hline & Mean value $\left(\mathbf{m g ~ k g}^{-1}\right.$ solution$)$ & RSD $(\boldsymbol{\%})$ \\
\hline LOD $(\mathbf{S} / \mathbf{N}=\mathbf{3})^{\mathrm{a}}$ & 1.3 & 8.6 \\
LOD $(\mathbf{3 ~ S b ~ / a ~})^{\mathrm{b}}$ & 1.1 & 13.9 \\
LOQ $(\mathbf{S} / \mathbf{N}=\mathbf{1 0})^{\mathrm{a}}$ & 4.5 & 14.7 \\
LOQ $(\mathbf{1 0 ~ S b ~ / a ~})^{\mathbf{b}}$ & 3.6 & 15.2 \\
\hline
\end{tabular}

Note: ${ }^{a}$ nine replicates.

${ }^{\mathrm{b}}$ three replicates. 
2

3 4

5

6

7

8

9

10

11

12

13

14

15

16

17

18

19

20

21

22

23

24

25

26

27

28

29

30

31

32

33

34

35

36

37

38

39

40

41

42

43

44

45

46

47

48

49

50

51

52

53

54

55

56

57

58

59

60

Table 4

\begin{tabular}{ccc}
\hline Concentration level $\left(\mathbf{m g ~ k g}^{-1}\right.$ olive oil) & Mean Recovery $(\%)^{\mathrm{a}}$ & RSD (\%) \\
\hline 33.8 & 85.3 & 1.2 \\
59.4 & 95.6 & 1.9 \\
99.4 & 100.7 & 2.4 \\
198.3 & 99.9 & 1.4 \\
\hline
\end{tabular}

Note: ${ }^{a}$ three replicates. 
Table 5

\begin{tabular}{|c|c|c|c|c|c|c|c|c|c|}
\hline \multirow{3}{*}{$\begin{array}{c}\text { Plasticizer } \\
\text { ESBO } \\
\text { LOQ: } 15.9(\mathrm{mg} / \mathrm{kg})\end{array}$} & \multicolumn{9}{|c|}{ Mean value (mg Kg ${ }^{-1}$ food simulant) ${ }^{\mathrm{a}}$} \\
\hline & \multirow{2}{*}{$\begin{array}{c}\begin{array}{c}\text { Pickled } \\
\text { Gherkins }\end{array} \\
<\text { LOQ }\end{array}$} & \multirow{2}{*}{$\frac{\text { Asparagus }}{\text { ND }}$} & \multirow{2}{*}{$\begin{array}{c}\text { Jam } \\
<\text { LOQ }\end{array}$} & \multicolumn{2}{|c|}{ Pate } & \multicolumn{2}{|c|}{ Pesto sauce } & \multicolumn{2}{|c|}{ Mayonnaise } \\
\hline & & & & $676 \pm 282$ & $94 \pm 49$ & $18 \pm 18$ & $<\mathrm{LOQ}$ & $71 \pm 24$ & $<\mathrm{LOQ}$ \\
\hline $\begin{array}{c}\text { DBS } \\
\text { LOQ: } 0.006(\mathrm{mg} / \mathrm{kg})\end{array}$ & ND & ND & ND & ND & ND & ND & ND & $2 \pm 2$ & $0.4 \pm 0.2$ \\
\hline$\underset{\text { LOQ: } 0.01(\mathrm{mg} / \mathrm{kg})}{\text { ATBC }}$ & ND & $1.2 \pm 0.1$ & ND & $22 \pm 19$ & $8 \pm 2$ & $285 \pm 12$ & $19 \pm 3$ & ND & ND \\
\hline $\begin{array}{c}\text { DOA } \\
\text { LOQ: } 0.01(\mathrm{mg} / \mathrm{kg})\end{array}$ & ND & ND & ND & ND & $0.23 \pm 0.05$ & ND & $0.23 \pm 0.01$ & $0.23 \pm 0.01$ & $0.53 \pm 0.04$ \\
\hline \multicolumn{2}{|c|}{ ND: non detectable } & Alterna & ive fat $\mathrm{s}$ & nulant: etha & $10195 \% \mathrm{v} / \mathrm{v}$ & \multicolumn{4}{|c|}{ Alternative fat simulant: iso-octane } \\
\hline
\end{tabular}

Note: ${ }^{a}$ three replicates. 


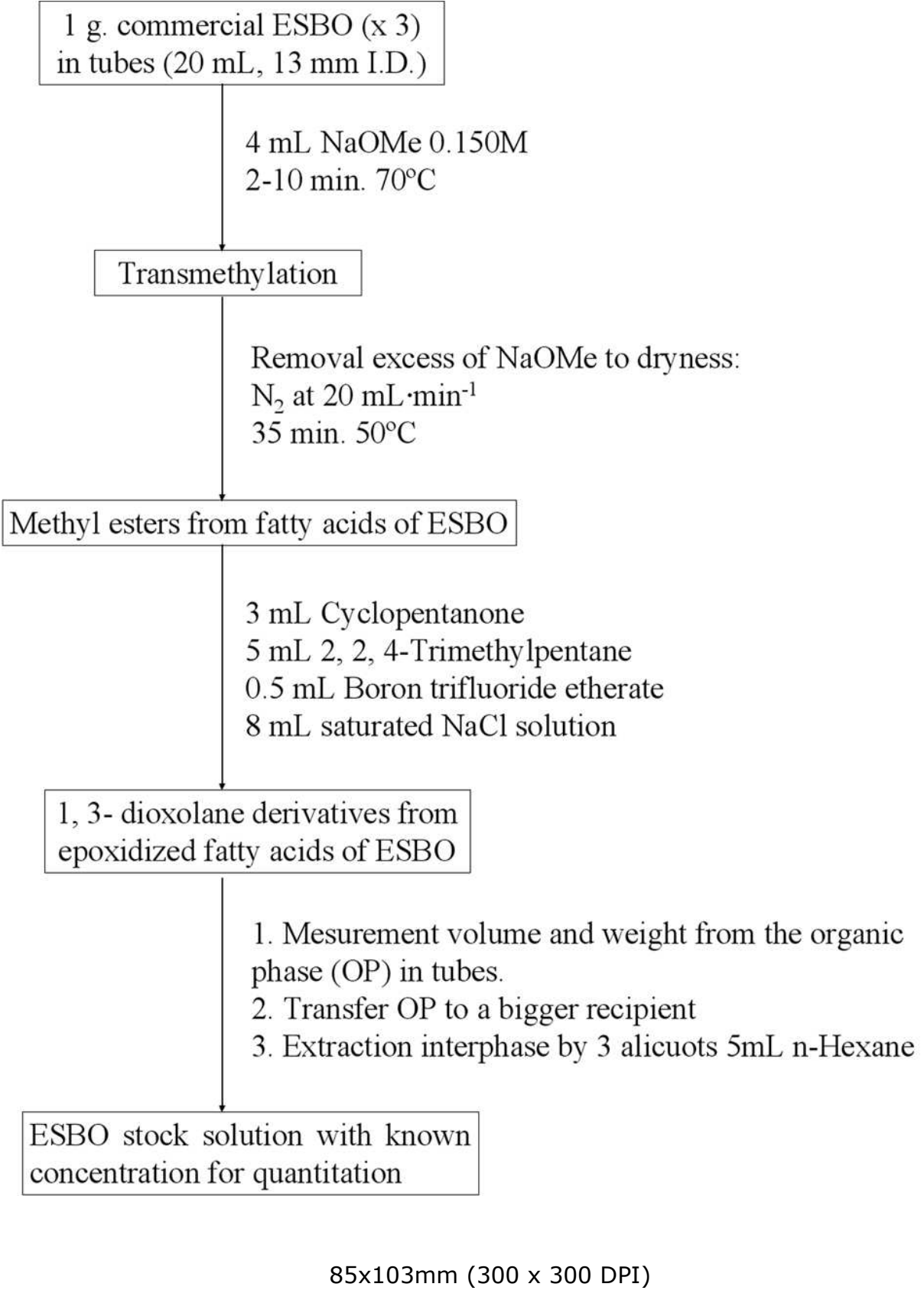

1. Mesurement volume and weight from the organic phase $(\mathrm{OP})$ in tubes.

2. Transfer OP to a bigger recipient

3. Extraction interphase by 3 alicuots $5 \mathrm{~mL}$ n-Hexane

ESBO stock solution with known

concentration for quantitation

$85 \times 103 \mathrm{~mm}(300 \times 300$ DPI $)$ 


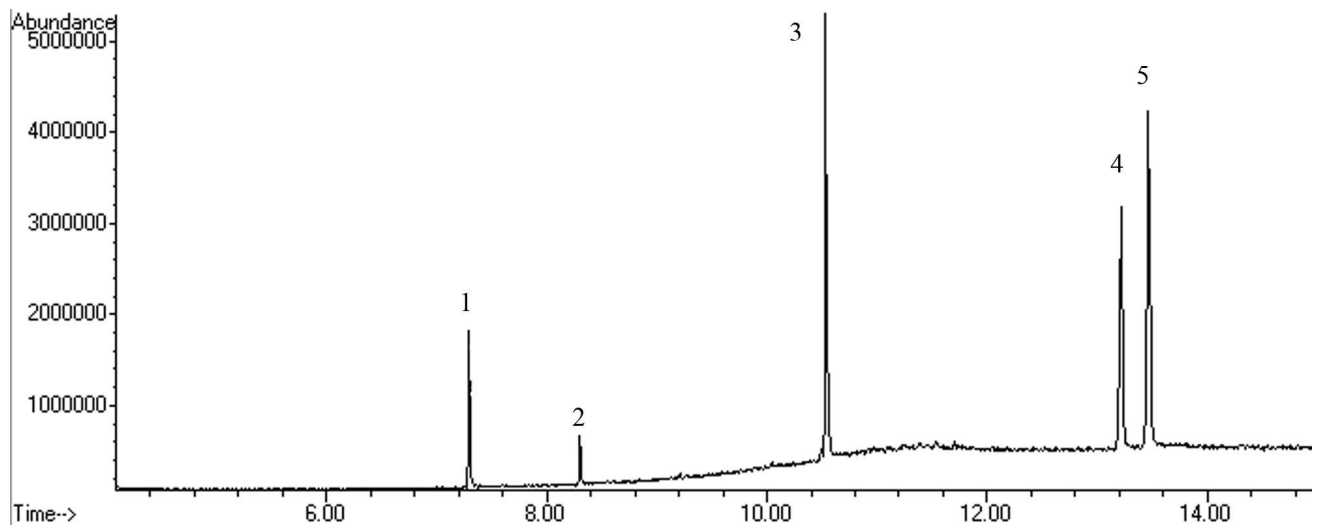

$170 \times 67 \mathrm{~mm}(300 \times 300 \mathrm{DPI})$ 
1

2

3

4

5

6

7

8

9

10

11

12

13

14

15

16

17

18

19

20

21

22

23

24

25

26

27

28

29

30

31

32

33

34

35

36

37

38

39

40

41

42

43

44

45

46

47

48

49

50

51

52

53

54

55

56

57

58

59

60

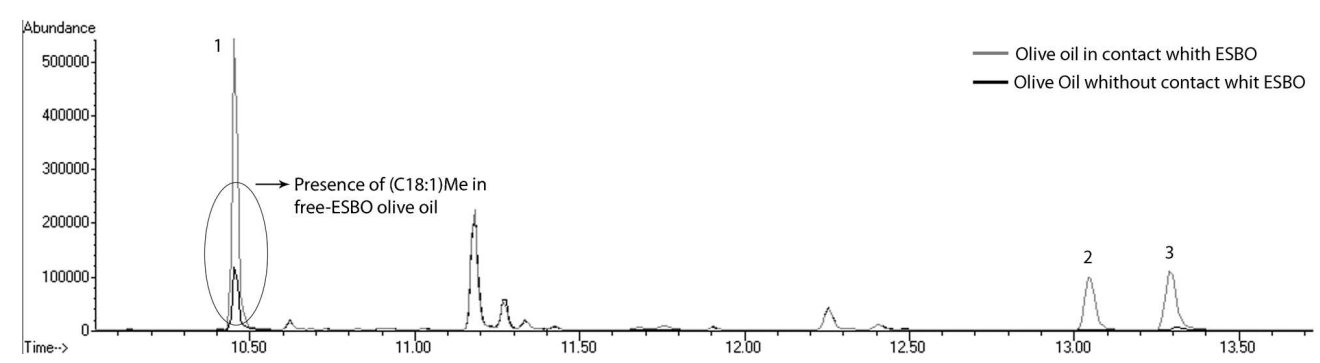

$170 \times 43 \mathrm{~mm}(300 \times 300$ DPI $)$ 


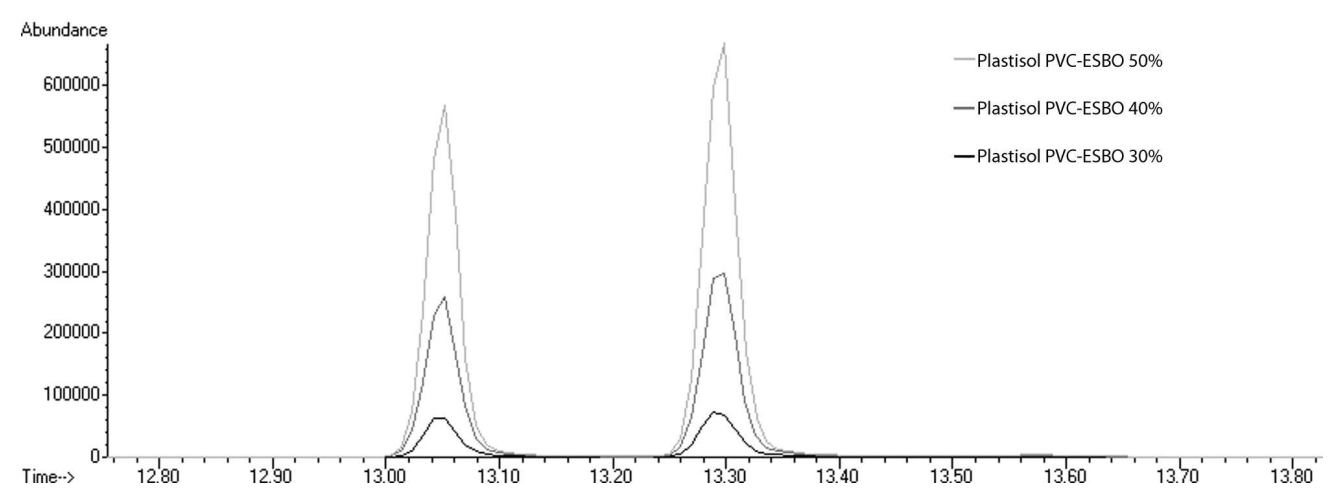

$170 \times 60 \mathrm{~mm}(300 \times 300 \mathrm{DPI})$ 